\title{
Review on Solar Air Conditioning with Desiccant Wheel
}

\author{
Sunil S. Miskin, Onkar P. Dhudhane, Abhishek H. Vedpathak, \\ Yogesh R. Barkul, Prof. Sachin M. Kale, Prof. Subhash V. Jadhav
}

\begin{abstract}
Making progress toward eco-friendly and checking anyway much essentialness as could sensibly be normal has transformed into the purpose of assembly as per the world. In this paper we give evaluate working and principals of sun controlled cooling. There are various source of essentially available to us that will direct our regular resources and cut down on risky transmissions that are eliminate climate condition. Various moving powers and by open to individuals and organizations who execute the usage of these earth very much arranged source of essentials. Our arrangement and improvement of a sun situated desiccant atmosphere control framework is another decision to cooling that uses far less power and moreover uses imperatives from the sun to run the system. We set out to make an atmosphere control framework that does not make any dangerous outpourings and wipes out the power cost to a home loan holder. The solar desiccant constrained air framework uses sun-based power as the essential imperatives source to help in the thermodynamic warmth trade process similarly as warmth trade models to change over including air into cool air. With our created structure we have seen temperature similarly as moisture level drops all through the desiccant cooling system.
\end{abstract}

Index Terms - Air-conditioner, solid desiccant wheel, desiccant cooling system, Absorption and regeneration.

\section{INTRODUCTION}

Highlight The interest for cooling is expanding because of the impact of environmental change and a worldwide temperature alteration. On the off chance that despite everything we depend on the traditional electric cooling however power is produced from non-renewable energy sources, the ozone depleting substance outflow would ceaselessly decline a worldwide temperature alteration,

Mr. Sunil S. Miskin, Students, Department of Mechanical Engineering, SVERI's College of Engineering, Pandharpur, Solapur, Maharashtra State, India

Mr. Onkar P. Dhudhane, Students, Department of Mechanica Engineering, SVERI's College of Engineering, Pandharpur, Solapur, Maharashtra State, India

Mr. Abhishek H. Vedpathak, Students, Department of Mechanical Engineering, SVERI's College of Engineering, Pandharpur, Solapur, Maharashtra State, India

Mr. Yogesh R. Barkul, Students, Department of Mechanical Engineering, SVERI's College of Engineering, Pandharpur, Solapur, Maharashtra State, India

Prof. Sachin M. Kale, Asst. Professor, Department of Mechanical Engineering, SVERI's College of Engineering, Pandharpur,Solapur, Maharashtra State, India

Prof. Subhash V. Jadhav, Asst. Professor, Department of Mechanical Engineering, SVERI's College of Engineering, Pandharpur,Solapur, Maharashtra State, India thusly, the interest of cooling would be additionally expanded. In subtropical urban communities, cooling is a standard arrangement for structures. Nonetheless, cooling would generally take up half of structure power utilization.

\section{LITERATURE REVIEW}

Factor H M (1977) ${ }^{[1]}$ this paper describes the design of a liquid desiccant airConditioning system using low grade heat resource which employs environmental friendly, ozone safe working substance. The main advantage of this air conditioning is that it can driven by low grade heat sources such as solar energy this research shows that a growing number of air conditioning , particularly in hot and humid climates such as south china, requires large amount of electric energy. The energy system encounters peak loads in hot summer days and often faces with brown out situations, which indicates it is barely capable of meeting the demand. At last it concludes that the system can handle both latent and sensible heat load for a room without any other refrigeration method. It is practically favorable for efficient utilization of heat source with varying temperature such as solar energy.

YellottJL(1984) $)^{[2]}$ this has been conducted into the application of indirect evaporative cooling in fulfillment of variable cooling load of typical Iraqi dwelling. Indirect evaporative cooling is good suited for dry temperate climates. In this filed Australians have been the most innovative designer of successful indirect evaporative air force. This review paper shoes that in order to meeting the cooling load by ventilation only outdoor air temperature must be lower than the design indoor temperature of $25.5 \mathrm{C}$. this review paper conclude that the peak load and daily total load of house were least when the long side of the building were facing north and south, with pick load occurring in the late afternoon regardless of the house orientation . system operation which provide a lower variation in the supply of air temperature result in a lower variation in the supply of air demand over the day .

Khalid A. $(2000)^{[3]}$ the present study has been conducted into the application of the indirect evaporative cooling in filled of the variable cooling load of a typical Iraqi dwelling. The results showed that indirect evaporative cooling would result in a comfortable indoor condition for most periods of system operation. Also, the results have shown that the coincident of performance tends to be very high because the system consumes only fan and water pumping power. This review concludes that the peak load and daily total load of the house were least when the long sides of the building were facing 


\section{Review on Solar Air Conditioning with Desiccant Wheel}

north and south, with the peak load occurring in the late afternoon regardless of the house orientation. The profile of the supply air demand follows the same trend as the cooling load profile. The corresponding times of the minimum and maximum points in the two profile are coincident with each other.

S.P. Halliday $(2002)^{[4]}$ they developed the first desiccant cooling cycle in Sweden. In that the mostly pointed the feasibility of using the solar study to desiccant cooling cycle. The desiccant wheel can be utilized both to cool and dehumidify the air. In that setup solar collector arranged for regenerative coil. Suppose in system air are supply through the wheel like $23 \mathrm{C}$ and its gives cooled output supply are reducing i.e. $17 \mathrm{C}$. It reduce framework working expenses roughly $20 \%$ of the arrival air flow by-passes the recovering loop and the desiccant wheel. The result shown that by experimentally, in summer time $23 \mathrm{C}$ temperature is achieved by using minimum external cooling coil and heat energy. And mainly $23 \%$ gas energy resources are saving. After that same experimental result are taken by 12 months, in that maximum $70 \%$ are reeducation gas utilized by solar energy sources. So that solar energy is mostly capable for both climates, mostly the heat is required for winter season and more capable this energy in summer times.

J.R. Camargo, (2005) $)^{[5]}$ In this review paper evaporative cooling operates using water and air working fluid. This paper aims to analyze the influence of some operation parameters, such as the reactivation temperature of the absorbent, and relationship between reactivation air flow and the process air flow $(\mathrm{R} / \mathrm{P})$ on the performance of the system. New technology using desiccant dehumidification applied to evaporative cooling system for human thermal comfort have been developed.A typical configuration uses a rotary desiccant wheel that moves slowly and continuously between two crosswise air fluxes. This paper presents an air conditioning system that couples a desiccant dehumidification equipment to indirect and direct evaporative coolers. In this system occurs a dehumidification by adsorption in a counter flow rotary heat exchanger following the evaporate cooling of the air using direct and indirect evaporative coolers.

A.E. Kabeel $(2007)^{[6]}$ studied the honeycomb desiccant turning wheel is developed and is used for the recovery and ingestion forms. And air flow and solar radiation effect on the system of absorption process. By using the empirical equation determined by wheel effectiveness for regeneration and absorption process. In that supplement for desiccant is conventional vapor compression system are used. In that through latent heat removed and for high loading of latent heat control humidify in better as compare to vapor compression system. In that performance of the regenerator expanded as the airflow rate also increments. The result shown that, the humidity difference is higher in regeneration process compared with the absorption process its value approximately equals twice the original value. The wheel effectiveness is higher for absorption process compared with regeneration process. They concluded that the system ishighly effective in the regeneration process for all flow rates compared with the absorption process. And the cooling impact approach esteems were gotten at various air flow rate and solar based radiation power.

Cun_Nan Li1,(2007) ${ }^{[7]}$ This paper describe Design of Liquid Desiccant Wheel has following Advantages, One of the main advantages is that it can be driven by low grade heat sources, such as waste heat, solar energy, etc. Another advantage lies in the fact that the liquid desiccant system is able to capture and remove airborne microorganisms, so it can improve the indoor air quality. The liquid desiccant air conditioning system described in this paper can handle both latent and sensible heat load of the conditioned space without any other auxiliary refrigeration methods. This result in the system can handle both latent and sensible heat load for the room without any other refrigeration method. The Coefficient of the Performance (COP) of the device can be up to 0.8 when the heat source temperature reaches 70ć.

A. Khalid, M. Mahmood(2009) ${ }^{[8]}$ they conducted the experiment in TRNSYS for Pre-cooled hybrid desiccant cooling system in Pakistan. In that hybrid desiccant wheel for heat and working for the performance of cycle. In that experimental setup two ducts connecting for ventilation and fans are used for regeneration airstream pass. The following mistake in the determined coefficient of execution dependent on essential vitality utilization, COP relied upon the blunder or vulnerability in the individual essential estimated amounts. The result shown that, indirect regenerative cooler temperature dropped by $15 \%$ in regenerative temperature. It concludes that direct evaporative are replaced by indirect evaporative it found that $15 \%$ dropped by regenerative temperature and while the decrease in dehumidification was only $6 \%$.

H. Parmar (2012) ${ }^{[9]}$ proposed that desiccant wheel is the best option for the alternative cooling system and for that DCS using $80 \%$ effective of ECW in a warm and humid climate. In that DCS inner surface are honeycomb structure and its temperature range of $80 \mathrm{C}$ to $90 \mathrm{C}$. The ratio of the regeneration air flow to process air flow increased when the regeneration power also increased. In that DCS silica gel material are used for the best cooling parameter. The specific humidity increases when the regeneration of desiccant wheel power decreases. In that condition, the $21.39 \%$ of specific humidity decreases in Mumbai and it was observed that best climate condition for India. In that conclude that the $\mathrm{R} / \mathrm{P}$ ratio are optimum for better performance for DCS and due to that regenerative of heat also increases.

Mario El Hourani,(2014) ${ }^{[10]}$ This study examines the design and operation of air conditioning system that uses $100 \%$ fresh air and integrates solid desiccants dehumidification system with two stageSystem. in this system small amount of power required for to operate fan. it uses desiccant wheel for outdoor air dehumidification. in building sector major contributor to energy consumption worldwide.it uses $41.1 \%$ of total energyconsumption originate from two main sources, the supply and exhaust variable speed fans that require electrical energy to operate.Auxiliary heater that require gas thermal energy to heatthewater flowing from the storage tank in case 
of solar energy deficiency.From this review we conclude that the two-stage evaporative cooling system is feasible for Lebanese office.Also, it requires lower running cost.

Ravi Gugulothu (2015) ${ }^{[11]}$ In this paper it is said that solar energy is more and more attention in the world. It is observed that the energy and water are basic need for all of us to lead normal life on this earth. Solar energy technology and its uses are very important and useful for the developing and under developing country to sustain their energy lead the main motivation for solar cooling system by renewable heat sources that is low grade heat from solar collectors. Solar cooling is good example of addressing climate change.

ZouaouiAhlem,(2015) ${ }^{[12]}$ Camargo studied a typical configuration of a desiccant evaporative cooling system using a rotating desiccant wheel where the process air is dehumidified then it is cooled in an indirect evaporative cooling and in a direct evaporative cooling to be introduced to the conditioned room in thermal conditions for human thermal comfort. The adsorbent utilized is silica gel with a low regeneration temperature (varying from 70 to $150^{\circ} \mathrm{C}$ ). In this study, an exegetics manufacturing cost method (EMC) is used.Hybrid air conditioning system using $100 \%$ fresh air and integrating a silica gel solid desiccant dehumidification system with a two-stage evaporative cooling system was examined recently. The system was installed in an office space in Beirut. The two-stage system realized a $16.15 \%$ reduction in energy consumption and a $26.93 \%$ reduction in water consumption in comparison with a single-stage evaporative cooling system at the same condition of thermal comfort.

Yi Chen,Weichen $(2017)^{[13]}$ in subtropical areas,such as Hong Kong,the cooling season is Long. Energy consumption of the air conditioning system accounted for about $54 \%$ and $23 \%$ of total building Energy consumption in Hong-Kong in office and buildingsthe desiccant enhanced evaporative cooling system is proposed. As promising energy saving air conditioning as well as environmentallyfriendlyfrom this review it is seen that moisture removal rate of fresh air increase from 0 to $12 \mathrm{gm} / \mathrm{kg}$ with solar collector area increase from 0 to $50 \mathrm{~m}^{2}$.

Yasser Abbassi,(2017) ${ }^{[14]}$ In this review paper the COP of single stage system is higher than double stagesolar assisted cooling system is an attractive and cost-effective process. As well as environmentally friendly.Desiccant wheel has attracted more attention because of it required less spacefrom these review paper we conclude that by increasing regenerative temp and inlet flow rateif the desiccant material absorb ambient moisture sufficient it would be more beneficial to utilize single stage configurationdouble stage required more energy.in most cases constant cooling load COP of the system decreases when both ambient temp and humidity ratio increases.

AliAlahmer $\left((2019)^{[15]}\right.$ In these the result shows that the emission of $\mathrm{CO}_{2}$ saved $44 \%$ Of the primary energy consumption in typical office in Hong Kong. It was found that among the various desiccant material silica gel $3 \mathrm{~A}$ and silica gel RD perform better than other material. Silica gel desiccant is preferred when greater moisture removal is required at low inlet humidity higher regenerative air temp leads to an improvement of a dehumidification and reduction of thermal COP desiccant wheel has better moisture removal with low process volume flow ratewith the wheel rotation the moisture removal increases up to the maximum value at rotation speed $14 \mathrm{rpm}$ and then it is decreases.

\section{CONCLUSION}

From the literature review, we can observe that the main source of energy is solar energy and its mostly usage \& developing for new technologies. Solar energy is observed that renewable source energy. Solar energy is an incentive for the solar cooling system is the replacement of electricity.

This paper analyzes mainly the desiccant wheel and its thermodynamics conditions. Such way that other parameter also observed like $\mathrm{R} / \mathrm{P}$ ration relationship, evaporative cooler temperature, a process of air flows, a coefficient of performance(COP), a different temperature at various climate condition such as DBT, WBT, relative humidity, air velocity, humidification \& dehumidification.

An analyze result and discussion shows that solar cooling is the best example for any climate conditions and take care of environmental conditions. The system is supplied for best human thermal comfort for both climates such as summer time and winter. It is observed that used for long term practice and alternative for the conventional solar cooling system. So solar energy is cost-effective, best renewable and eco-friendly.

\section{REFERENCES}

[1] H M , Grossman G. A packed bed dehumidifier regenerator for solar air condictioner, $12^{\text {th }}$ IECEC paper 779079,1977,pp.

[2] Yellott JL, Gamero J. Indirect evaporative air coolers for hot, dry climates. ASHRAE Trans 1984;90(1B):139

[3] Khalid A. Joudi and Salah M. Mehdi, "Application of indirect evaporative cooling to variable domestic cooling load", Energy Conversion \& Management 41 (2000) 1931 \pm 1951

[4] S.P. Halliday, C.B. Beggs and P.A. Sleigh, "The use of solar desiccant cooling in the UK: a feasibility study", Applied Thermal Engineering 22 (2002) 1327-1338.

[5] J.R. Camargo, E. Godoy and Jr. C. D. Ebinuma, "An evaporative and desiccant cooling system for air conditioning in humid climates", Journal of the Brazilian society of Mechanical science and Engineering 2005, vol.27, n.3, pp.243-247. ISSN 1678-5878.

[6] A.E. Kabeel, "Solar powered air conditioning system using rotary honeycomb desiccant wheel", Renewable Energy 32(2007) 1842-1857.

[7] Cun Nan Li,JianHua Liu, Si Chang Liu and Jun Chen, "A new AirConditioning system of liquid Desiccant and Evaporative cooling", The National High Technology Research and Development Program of China, No. 2007AA05Z211.

[8] A. Khalid, M. Mahmood, M. Asif and T. Muneer, "Solar assisted, pre-cooled hybrid desiccant cooling system for Pakistan", Renewable energy 34(2009) 151-157.

[9] H. Parmarand D.A. Hindoliya, "Performance of solid desiccant-based evaporative cooling system under the climatic zones of India", abstract/8/1/52/742212 by guest on 22 March 2019.

[10] Mario El Hourani, KamelGhali and NesreenGhaddar, "Effective desiccant dehumidification system with two stage evaporative cooling for hot humid climates", Energy and Buildings 68(2014) 329-338.

[11] Ravi Gugulothu, Naga Sarada, Somanchi, HimaBinduBanoth and KisanBanothu, "A Review on solar powered Air- Conditioning System", Procedia Earth and planetary science 11(2015) 361-367

[12] ZouaouiAhlem, Leila Zili-Ghedira ,Sassi Ben and Nasrallah Camargo "Desiccant-Based Dehumidification And Direct/Indirect Evaporative Cooling Technologies", 2015 6th International Renewable Energy Congress (IREC). 
[13] Yi Chen,WeichenYu,PeishiWu,Hongxing Yang and YimoLuo, "Energy performance of solar assisted desiccant enhanced evaporative cooling air condition system", Procedia Engineering 205(2017) 4195-4202.

[14] Yasser Abbassi,EhsanBaniasadi and HoseinAhmadikia, "Comparative performance analysis of different solar desiccant dehumidification systems", Energy and Buildings 150(2017) 37-51

[15] AliAlahmer,SamehAlsaqoorandGabriel Borowski, "Effect of parameter on moisture removal capacity in desiccant cooling systems", Case study in Thermal Engineering 13(2019) 100364.

[16] Y. Cheng, Z. Lin, A.M.L. Fong Effects of temperature and supply airflow rate on thermal comfort in astratum-ventilated roomBuild. Environ., 92 (2015), pp. 269-277

[17] K.F. Fong, T.T. Chow, C.K. Lee, Z. Lin, L.S. ChanComparative study of different solar cooling systems for buildings in subtropical cityEnergy, 84 (2) (2010).

[18] U.S. Department of Energy, 2011 Buildings Energy Data Book, Table 1.1.3, D\&RInternational Ltd., 2012.

[19] W. Chakroun, N. Ghaddar, K. Ghali, Chilled ceiling and displacement ventilationBuilding and Environment 44 (2009) 826-838.[4] M Hammoud, K. Ghali, N. Ghaddar, Optimized Operation of Solar Hybrid

[20] GeorgeEitelhube, "Seed Fund Winners - NOMADD: The No-water Mechanical Automated Dusting Device", King Abdullah University of Science and Technology (KAUST), energy and sustainability are primary research drivers, 2012. 